\title{
Evaluation of Tooth Size and Dental Arch Ratio in Bengali Population Somple
}

\author{
Dr Dhyan Chand Murmu,' Dr Swati Saraswata Acharya, ${ }^{2}$ Dr Anu Ranjan Das, ${ }^{3}$ Dr Bides Bhaumik ${ }^{4}$ \\ 1.2 Senior Lecturer, Dept. of Orthodontics \\ Institute of Dental Sciences, Bhubaneswar, India \\ 3.4Professor, Dept of Orthodontics, \\ Dr R Ahmed Dental College, Kolkata, India
}

Correspondence: swati.acharya.tmdc@gmail.com

\section{ABSTRACT}

Introduction: In order to maintain the proper relationship between upper and lower arch, Bolton proposed anterior ratio and overall ratio.

Objective: To evaluate and compare the tooth size and arch size discrepancies between normal cases and Class I crowded cases of the Bengali population. To determine Bolton's overall ratio and anterior ratio in the normal sample, and to identify the possible variation in tooth-arch size ratio in subjects in Bengali population.

Materials \& Method: A total of 60 maxillary and mandibular pretreatment dental study casts were taken and divided into control group and study group. The descriptive statistics in respect of Bolton's anterior ratio and overall ratio were calculated. The t-test was done for the statistical difference between the two mean values.

Result: Bolton's ratios in Bengali population sample values were found to be similar to the original data of Caucasian population. Females showed a tendency of smaller teeth than the males.

Conclusion: Bolton's ratios could be consistent to use in the orthodontic diagnosis of Bengali population. It supports the concept that females showed smaller teeth than the males.

Key words: Bolton anterior ratio, Bolton overall ratio, inter-arch relationships

\section{INTRODUCTION}

Facial esthetics is dependent intimately on architectural relationship of facial skeleton so as to serve the base for structural balance. The proportional relationship of tooth material of the upper arch to the lower arch is the prerequisite to achieve functional occlusion and healthy maintenance of the system. The presence of inter-arch tooth size discrepancy leads to mal-relationship between the arches with decreased functional efficiency and disfigurement in esthetic harmony. Tooth size exhibits a range of variation among individuals and in populations. Accumulated evidence indicate that tooth size reflects a complex interaction between genetic and environmental factors.' A proportionate relationship between mesio-distal widths of maxillary dentition to that of the mandibular dentition favours an optimal post-treatment occlusion. ${ }^{2}$

As with other human attributes, there is a variation in tooth size between male and female teeth. ${ }^{3}$ Whereas the upper lateral incisors and lower incisors are the most homogenous. ${ }^{4}$ Although significant differences in tooth size exist between male and female, there is no evidence of difference in upper to lower anterior tooth size proportions. ${ }^{5,6}$

Identification of a suitable arch form and dimension is a key aspect of achieving stable, functional, and esthetic arch form in orthodontic diagnosis and treatment.? Furthermore, failure to customize the arch form creates the probability of relapse leading to poor prognosis. It is important to select the shape that closely matches patient's pretreatment arch form, conforming to ethnicity and malocclusion type..$^{8} \mathrm{~A}$ relative harmony in the mesio-distal dimension of the maxillary and mandibular teeth is a major factor in coordinating posterior inter-digitations, overbite and overjet in centric occlusion. ${ }^{?}$

Bolton $^{10}$ in 1958 studied 55 Caucasian subjects with excellent occlusion using mesio-distal crown width of 12 teeth (from first permanent molar on one side to other side). Bolton obtained an overall ratio of $91.36 \pm 1.91 \%$. Similarly using six anterior teeth (permanent canine on one side to other side), obtained an anterior ratio of $77.26 \pm 1.65 \%$. This analysis is commonly used as a valuable diagnostic aid in orthodontics. These ratios gave a definite percentage of 
mandibular to maxillary tooth size. The reliability of Bolton ratio may be an over simplification when they are used flatly in any population irrespective of ethnic variation.

The objective of this study was to evaluate and compare the tooth size and arch size discrepancies between normal cases and Class I crowded cases of the Bengali population, to determine Bolton's overall ratio and anterior ratio in the normal sample of Bengali population, and to identify the possible variation in tooth-arch size ratio in subjects in Bengali population.

\section{MATERIALS AND METHOD}

Samples were screened among the patients attending Department of Orthodontics, Dr R Ahmed Dental College, Kolkata, India. A total of 60 samples were taken and divided into two groups: control group comprising of 20 samples (10 females and 10 males) and study group comprising of 40 samples (20 males and 20 females). The control group comprised of normal Class I occlusion without crowding and malocclusion, whereas study group comprised of Class I malocclusion with crowing of the anterior teeth.

The samples were selected on the basis of inclusion criteria of the healthy subjects of Bengali origin and habitat of Bengal of the age ranging from 12-18 years. All subjects were without any previous history of orthodontic treatment. All subjects had completed permanent dentition excluding third molars with the molar relation in Angle's class I. All subjects were without clinically visible dental caries, periodontal disease, proximal restorations, attrition, stripping of proximal areas and without any craniofacial and dental anomalies.

Dental stone study models were made using alginate impression material. Tooth size was measured directly on study model using Boley gauge with a digital vernier scale (Workzone) of $0.05 \mathrm{~mm}$ accuracy.

Tooth size or mesio-distal tooth width was obtained by measuring the maximum distance between mesial and distal contact points with the caliper tips placed perpendicular to the long axis of each tooth. The sharp tips of the calipers facilitated accuracy. A precision reading to the nearest 0.1 $\mathrm{mm}$ was used to measure the tooth size. A single investigator measured each arch twice to avoid inter-operator variability. If the second measurement differed by more than $0.2 \mathrm{~mm}$ from the first measurement, the tooth was measured again. The measurements included the mesio-distal widths of all maxillary and mandibular teeth from the right first permanent molar to left first permanent molar.

Bolton's anterior ratio i.e. ratio between the mesio-distal widths of 6 anterior mandibular teeth and mesio-distal widths of 6 anterior maxillary teeth and Bolton's overall ratio i.e. the ratio between mesio-distal widths of 12 mandibular teeth and mesio-distal widths of 12 maxillary teeth from right first permanent molar to left first permanent molar were calculated.

Descriptive statistics including mean, standard deviation, range, standard error of mean, co-efficient of correlation in respect of Bolton's anterior ratio and overall ratio were calculated using Microsoft Excel 2007 and Minitab version 15.0 programs. The coefficient of variation was calculated to determine the tooth size ratios. Student's t-test was used to analyze the statistical difference between the means.

\section{RESULT}

The obtained mean values with standard deviation for normal Class I Bengali population sample for Bolton's anterior ratio were $78.15 \pm 2.91$ and $79.02 \pm 2.72$ for female and male respectively. Similarly mean values with standards deviation for overall ratio were $91.72 \pm 2.04$ and $92.85 \pm 2.31$ for females and males respectively. The result showed no significant difference between male and female Bengali samples in anterior as well as overall ratios (Table 1). So for the Bolton ratios of both gender groups were combined and new anterior and overall ratio were calculated as 78.59 and 92.29 respectively and these ratio were compared with original Bolton ratio of Caucasian population (Table 2).

Table 1: Anterior Ratio and Overall Ratio in the Bengali Sample by Sex

\begin{tabular}{|c|c|c|c|c|c|c|c|c|c|c|}
\hline & \multicolumn{2}{|c|}{ Range } & \multicolumn{2}{|c|}{$\begin{array}{l}\text { Mean } \\
\text { Value }\end{array}$} & \multicolumn{2}{|c|}{$\begin{array}{l}\text { Standard } \\
\text { Deviation }\end{array}$} & \multicolumn{2}{|c|}{$\begin{array}{c}\text { Standard Error of } \\
\text { Mean }\end{array}$} & \multicolumn{2}{|c|}{$\begin{array}{l}\text { Coefficient } \\
\text { Variation }\end{array}$} \\
\hline & Male & Female & Male & Female & Male & Female & Male & Female & Male & Female \\
\hline Anterior Ratio & $74.86-3.09$ & $73.75-3.22$ & 79.02 & 78.15 & 2.72 & 2.91 & 0.86 & 0.92 & 3.44 & 3.73 \\
\hline Overall Ratio & $88.64-5.58$ & $88.19-4.12$ & 92.85 & 91.72 & 2.31 & 2.04 & 0.73 & 0.64 & 2.79 & 2.23 \\
\hline
\end{tabular}

Anterior Ratio t-value $=0.70 p$-Value $=0.494$; Overall Ratio t-value $=1.16 p$-Valve $=0.263$

Table 2: Comparison of Bolton's Caucasian Ratios with the Bengali sample

\begin{tabular}{|l|c|c|c|c|c|c|c|c|c|c|}
\hline & \multicolumn{2}{|c|}{ Range } & \multicolumn{2}{c|}{$\begin{array}{c}\text { Mean } \\
\text { Value }\end{array}$} & \multicolumn{2}{c|}{$\begin{array}{c}\text { Standard } \\
\text { Deviation }\end{array}$} & $\begin{array}{c}\text { Standard Error of } \\
\text { Mean }\end{array}$ & $\begin{array}{c}\text { Coefficient } \\
\text { Variation }\end{array}$ \\
\cline { 2 - 13 } & Caucasian & Bengali & Caucasian & Bengali & Caucasian & Bengali & Caucasian & Bengali Caucasian & Bengali \\
\hline Anterior Ratio & $74.5-80.4$ & $73.80-83.22$ & 77.26 & 78.59 & 1.65 & 2.78 & 0.22 & 0.62 & 2.14 & 3.54 \\
\hline Overall Ratio & $87.5-94.8$ & $88.20-95.60$ & 91.36 & 92.29 & 1.91 & 2.20 & 0.26 & 0.49 & 2.09 & 2.39 \\
\hline
\end{tabular}

Anterior Ratio t-value $=2.11 \quad \mathrm{p}$-value $=0.046 \mathrm{DF}=24$, Overall Ratio $t$-value $=1.80 \mathrm{p}$-value $=0.082 \quad \mathrm{DF}=30$ 
The parameters of Bolton ratios in Bengali population sample shows that the upper and lower teeth were normally distributed in the control group having good occlusion relationship and they ranged from 73.80 to 83.22 with a mean value of 78.59 and a low standard deviation of 2.78 . The overall ratio ranged from 88.20 to 95.60 with a normal distribution with a mean value of 92.29 with standard deviation of 2.20 , also indicating low variability (Table 2).

The comparison with the original Bolton data showed minimally higher range values for the anterior and overall ratio and the reports also do not show any clinical significance between anterior and overall Bolton ratio between Bengali and Caucasian population samples.

Table 3 depicts the mean values of individual tooth size on the right sided arch of male and female control group (normal/noncrowded) and study group (Class I/crowded).

Table 3: Mean values of individual tooth size of male and female control group and study group

\begin{tabular}{|c|c|c|c|c|c|c|c|c|c|c|c|c|c|}
\hline \multirow{3}{*}{ Group } & \multirow{3}{*}{ Tooth } & \multicolumn{6}{|c|}{ Maxillary arch } & \multicolumn{6}{|c|}{ Mandibular arch } \\
\hline & & \multicolumn{3}{|c|}{ Male } & \multicolumn{3}{|c|}{ Female } & \multicolumn{3}{|c|}{ Male } & \multicolumn{3}{|c|}{ Female } \\
\hline & & $\mathrm{N}$ & Mean & SD & $\mathrm{N}$ & Mean & SD & $\mathrm{N}$ & Mean & SD & $\mathrm{N}$ & Mean & SD \\
\hline $\mathbf{N}$ & $\mathrm{CI}$ & 10 & 8.030 & 0.354 & 10 & 8.585 & 0.912 & 10 & 5.260 & 0.141 & 10 & 5.260 & 0.141 \\
\hline C & & 20 & 9.239 & 0.494 & 20 & 8.948 & 0.683 & 20 & 5.8514 & 0.3662 & 20 & 5.588 & 0.325 \\
\hline $\mathbf{N}$ & LI & 10 & 6.260 & 0.311 & 10 & 7.170 & 0.665 & 10 & 5.810 & 0.354 & 10 & 5.810 & 0.354 \\
\hline C & & 20 & 7.589 & 0.488 & 20 & 7.373 & 0.683 & 20 & 6.266 & 0.436 & 20 & 6.249 & 0.449 \\
\hline $\mathbf{N}$ & Canine & 10 & 7.225 & 0.559 & 10 & 7.410 & 0.396 & 10 & 6.315 & 0.134 & 10 & 6.315 & 0.134 \\
\hline C & & 20 & 8.179 & 0.556 & 20 & 7.873 & 0.594 & 20 & 7.289 & 0.463 & 20 & 6.720 & 0.531 \\
\hline $\mathbf{N}$ & 1st Premolar & 10 & 6.125 & 0.304 & 10 & 6.725 & 0.106 & 10 & 6.380 & 0.453 & 10 & 6.380 & 0.453 \\
\hline C & & 20 & 7.408 & 0.451 & 20 & 7.365 & 0.665 & 20 & 7.539 & 0.423 & 20 & 7.396 & 0.496 \\
\hline $\mathbf{N}$ & 2nd Premolar & 10 & 6.140 & 0.410 & 10 & 7.710 & 0.070 & 10 & 6.125 & 0.276 & 10 & 6.125 & 0.276 \\
\hline C & & 20 & 6.876 & 0.400 & 20 & 6.876 & 0.602 & 20 & 7.491 & 0.517 & 20 & 7.124 & 0.406 \\
\hline $\mathbf{N}$ & 1st Molar & 10 & 9.860 & 0.198 & 10 & 9.435 & 0.070 & 10 & 10.755 & 0.389 & 10 & 10.755 & 0.389 \\
\hline C & & 20 & 10.431 & 0.681 & 20 & 10.017 & 0.523 & 20 & 11.096 & 0.675 & 20 & 10.747 & 0.667 \\
\hline
\end{tabular}

$\mathrm{N}$-Control group (Non-crowded); C-Study group (Crowded)

\section{DISCUSSION}

The study models were used to determine tooth size and inter-arch discrepancies in the present study. The study cast is the only noninvasive three dimensional records that provide information in orthodontic diagnosis and treatment planning. " Dental casts are still considered a vital diagnostic tool in orthodontic practice. They facilitate the analysis of tooth size and shape; alignment and rotations of the teeth, arch width, length, form and symmetry and the occlusal relationship. ${ }^{12}$

Proffit ${ }^{13}$ mentioned that approximately $5 \%$ of the population has some degree of disproportion among the size of individual teeth. So it is logical to measure the mesio-distal width of maxillary and mandibular teeth in normal as well as in moderate crowding cases of Bengali population. From these data Bolton ratios were calculated and compared with original values. The present study found that the Bolton's ratio values are similar to the original data of Caucasian population; and the anterior and overall ratio developed by Bolton can also be used on Bengali population.

\section{CONCLUSION}

The study revealed that females possess smaller teeth than males. There was no statistically significant difference between Bolton ratios of Bengali population with Caucasian population. 


\section{REFERENCES}

1. Hattab FN, Al-Khateeb S, Sultan I: Mesiodistal crown diameters of permanent teeth in Jordanians. Arch oral bio. 1996; 41:641-5.

2. Margherita S, Ayoub ME, Pardi VA, Cangialosi TJ. Mesiodistal crown dimensions and tooth size discrepancy of the permanent dentition of Dominican Americans. Angle Orthod 2000; 70:303-307

3. Carlos S, Savara BS. An analysis of permanent mesiodistal crown size. Am J Orthod. 1971; 59:488-500.

4. Richardson ER, Malhotra SK. Mesiodistal crown dimension of the permanent dentition of American Negroes. Am J Orthod. 1975; 68:157164.

5. Smith SS, Buschang PH, Watanabe E. Interarch tooth size relationships of 3 populations: Does Bolton's analysis apply. Am J Orthod. 2000; 117:169-174.

6. Nie, Qiong, Jiuxiang Lin. Comparison of Intermaxillary tooth size discrepancies among different malocclusion groups. Am J Orthod. 1999; 116: 539-544.

7. Banabilh SM, Rajion ZA, Samsudin R, Singh GD: Dental arch shape and size in Malay school children with Class II malocclusion. Aus Orthod J. 2006; 22: 99-103.

8. Kook Yoon-Ah, Nojima Kunihiko, Moon Hong-Beom, McLaughlin RP, Sinclair PM. Comparison of arch forms between Korean and North American white populations. Am J Orthod. 2004; 126:680-686.

9. Heusdens M, Dermaut L, Verbeeck R. The effect of tooth size discrepancy on occlusion: An experimental study. Am J Orthod. 2000; 117:184-191.

10. Bolton W. Disharmony in tooth size and its relation to the analysis and treatment of malocclusion. Am J Orthod. 1958; 28:113-130.

11. Huie-Ming Hou, Ricky Wing-Kit Wong, Urban Haggery: The uses of orthodontic study models in diagnosis and treatment planning. Hong Kong Dent J. 2006; 3:107-15.

12. Hasim HA, Al-Ghamdi S. Tooth width and arch dimensions in normal and malocclusion samples: An odontometric study. J Contemp Dent Pract 2005; 6(2):36-51.

13. Proffit WR, Fields HW, Sarver DM. Contemporary Orthodontics. 4th ed. Elsevier; 2007. 